\title{
Surfactants Affect Calcium Uptake from Postharvest Treatment of 'Golden Delicious' Apples
}

\author{
Stéphane Roy \\ Horticultural Crops Quality Laboratory and Electron Microscopy Laboratory, Beltsville Agricultural \\ Research Center, Agricultural Research Service, U.S. Department of Agriculture, Beltsville, MD 20705
}

William S. Conway, J. George Buta, and Alley E. Watada

Horticultural Crops Quality Laboratory, Beltsville Agricultural Research Center, Agricultural Research

Service, U.S. Department of Agriculture, Beltsville, MD 20705

Carl E. Sams

Department of Plant and Soil Science, The University of Tennessee, Knoxville, TN 37901

William P. Wergin

Electron Microscopy Laboratory, Beltsville Agricultural Research Center, Agricultural Research Service, U.S. Department of Agriculture, Beltsville, MD 20705

Additional index words. $\mathrm{CaCl}_{2}$, low temperature scanning electron microscopy, Malus domestica, pressure infiltration

\begin{abstract}
Golden Delicious' apples (Malus domestica Borkh) were dipped in either distilled water, methylene chloride, or one of the following surfactants: Brij 30, Tween 20, Tween 80, Tergitol 15-S-9, and Triton X-100. The fruit then were pressure-infiltrated with a $2 \%$ solution of $\mathrm{CaCl}_{2}$. Following 4 months storage at $\mathrm{o}^{\circ} \mathrm{C}$, fruit were removed and flesh $\mathrm{Ca}$ concentration analyzed. The fruit surface was observed using low-temperature scanning electron microscopy, and fruit were rated for surface injury. Brij 30 altered the epicuticular wax the least and resulted in the smallest increase in flesh Ca concentration and the softest fruit. Triton X-100 altered the epicuticular wax the most and resulted in the highest fruit flesh Ca concentration and firmest of the surfactant-pretreated fruit. Methylene chloride removed some of the epicuticular wax, and fruit pretreated with this solvent had the highest flesh Ca concentration and greatest firmness. However, all of the fruit treated with methylene chloride were severely injured.
\end{abstract}

Many physiological and pathological disorders of apples are related to the $\mathrm{Ca}$ content of the fruit tissue. Increasing the $\mathrm{Ca}$ content of apples maintains fruit firmness; decreases the incidence of various disorders, such as water core, bitter pit, and internal breakdown (Bangerth et al., 1972; Faust and Shear, 1968; Marlow and Loescher, 1984; Reid and Padfield, 1975); and reduces decay caused by postharvest pathogens (Conway et al., 1992). The apple flesh Ca concentration necessary to reduce pathological and physiological disorders is higher than that obtained through usual fertilizer regimes. Thus, several studies have investigated the effects of direct application of $\mathrm{CaCl}_{2}$ solutions to apples and the resulting effects on storage quality. Foliar sprays can increase the Ca content of apple fruit slightly (Drake et al., 1979), but these increases can vary from year to year depending on growing conditions (Glenn et al., 1985). Experimentally, pressure infiltration of apples with $\mathrm{CaCl}_{2}$ solutions increases the $\mathrm{Ca}$ concentration of fruit more effectively than spraying, dipping, or vacuum infiltration (Conway and Sams, 1983; Sams and Conway, 1984). However, inadequate Ca uptake is a problem for some lots of fruit, and excessive $\mathrm{Ca}$ uptake, resulting in fruit injury, is a problem for others.

The cuticle serves as the prime barrier to penetration of different solutes (Bukovac et al., 1981), and numerous studies have focused

Received for publication 27 Nov. 1995. Accepted for publication 1 July 1996. We express our appreciation to George A. Brown for valuable technical assistance. Use of company name or product by the U.S. Dept. of Agriculture does not imply approval or recommendation of the product to the exclusion of others that also may be suitable. The cost of publishing this paper was defrayed in part by the payment of page charges. Therefore, under postal regulations, this paper must be marked advertisement solely to indicate this fact. on cuticle structure, composition and penetration by components (Bukovac and Petracek, 1993; Glenn and Poovaiah, 1985; Knoche et al., 1994). Epicuticular waxes are known to reduce cuticular penetration by a wide range of solutes (Schonherr and Riederer, 1989). However, growing evidence suggests that cracks might provide a pathway for Ca penetration into apple fruit (Glenn et al., 1985; Harker and Ferguson, 1988, 1991; Roy et al., 1994a, 1995). Therefore, modifying the epicuticular wax without altering its protecting properties may allow increased and more uniform $\mathrm{Ca}$ uptake. Surfactants alter energy relationships at interfaces, thereby reducing surface tension (Rosen, 1978) and enhancing foliar absorption of biologically active compounds (Attwood and Florence, 1983).

Table 1. Hydrophile-lipophile balance number (HLB) and chemical description of the surfactants.

\begin{tabular}{|c|c|c|}
\hline Surfactant & HLB & Chemical description \\
\hline Brij 30 & 9.7 & $\begin{array}{l}\text { Polyoxyethylene (4) lauryl ether } \\
\mathrm{C}_{12} \mathrm{H}_{25}\left(\mathrm{OCH}_{2} \mathrm{CH}_{2}\right)_{4} \mathrm{OH}\end{array}$ \\
\hline Tween 20 & 16.7 & $\begin{array}{l}\text { Polyoxyethylene (20) sorbitan } \\
\text { monolaurateC } \mathrm{C}_{11} \mathrm{H}_{23} \mathrm{CO}_{2}\left(\mathrm{OCH}_{2} \mathrm{CH}_{2}\right)_{20} \\
\mathrm{C}_{6} \mathrm{H}_{9}(\mathrm{OH})_{3}\end{array}$ \\
\hline Tween 80 & 15.0 & $\begin{array}{l}\text { Polyoxyethylene (20) sorbitan } \\
\text { mono-oleateC }{ }_{17} \mathrm{H}_{33} \mathrm{CO}_{2}\left(\mathrm{OCH}_{2} \mathrm{CH}_{2}\right)_{20} \\
\mathrm{C}_{6} \mathrm{H}_{9}(\mathrm{OH})_{3}\end{array}$ \\
\hline Tergitol 15-S-9 & 13.3 & $\begin{array}{l}\text { Polyoxyethylene (9) sec-dodecyl } \\
\text { ether } \mathrm{C}_{12} \mathrm{H}_{25}\left(\mathrm{OCH}_{2} \mathrm{CH}_{2}\right)_{9} \mathrm{OH}\end{array}$ \\
\hline Triton X-100 & 13.5 & $\begin{array}{l}\text { Polyoxyethylene (10) tetra-methyl- } \\
\text { butylbenzene } \mathrm{C}_{8} \mathrm{H}_{17} \mathrm{C}_{6} \mathrm{H}_{4}\left(\mathrm{OCH}_{2}\right. \\
\left.\mathrm{CH}_{2}\right)_{10} \mathrm{OH}\end{array}$ \\
\hline
\end{tabular}


Our study examines the effect of various nonionic surfactants on postharvest pressure infiltration of $\mathrm{Ca}$ into apples. The physiochemical activity of these surface active agents on the fine structure of the epicuticular wax of the apple fruit surface also is examined. Our objective is to determine if $\mathrm{Ca}$ infiltration into fruit can be increased by pretreatment with surfactants without damage to the fruit surface.

\section{Materials and Methods}

'Golden Delicious' apples were harvested in the preclimacteric stage from a commercial orchard in Pennsylvania and were randomized. The fruit then were dipped in the following solutions for 3 min: distilled water, Brij 30, Tween 20, Tween 80, Tergitol 15S-9, and Triton X-100 (Table 1). The concentration of all surfactants was $0.2 \%(\mathrm{w} / \mathrm{v})$. In addition, one lot of fruit was not treated and another was dipped twice for $15 \mathrm{~s}$ in $\mathrm{CH}_{2} \mathrm{Cl}_{2}$. The fruit were allowed to dry, then pressure-infiltrated ( $3 \mathrm{~min}$ at $103 \mathrm{kPa}$ ) with a $2 \%$ solution (w/v) of $\mathrm{CaCl}_{2}$, and stored at $0{ }^{\circ} \mathrm{C}$.

After 4 months, the fruit were removed from storage and placed at $20^{\circ} \mathrm{C}$ for 1 week. Fruit were analyzed for Ca content and flesh firmness and were rated for injury. Samples from the apple surfaces were taken for low-temperature scanning elctron microscope observations; care was taken to avoid any mechanical damage to the fruit surface that may have occurred during harvest, transport, and preparation.

Calcium was analyzed after the peel and outer flesh were removed (to a depth of $2 \mathrm{~mm}$ ) with a mechanical peeler. The next $2 \mathrm{~mm}$ of flesh was similarly removed, immediately freeze-dried, and ground. One gram of this dried tissue was dry-ashed, dissolved in $8 \mathrm{ml}$ of $2 \mathrm{~N}$ hydrochloric acid, and filtered. The samples were analyzed for $\mathrm{Ca}$ content by inductively coupled plasma emission spectrometry. Calcium content was reported on a dry-mass basis. Each sample consisted of flesh from five apples, and each treatment consisted of four samples in each of three replications.

Firmness was measured at two opposite sites on the equator of each fruit (skin removed) using an electronic pressure tester (EPT1; Lake City Technical Products, Kelowna, B.C., Canada) interfaced to a personal computer. Twenty fruit were measured for each of the three replications of each treatment.

Fruit were visually rated for surface injury on a scale from 1 (severe) to 5 (no injury). The percentage of the 20 fruit per replication of each treatment showing any indication of injury also was recorded.

For low-temperature SEM observations, an Oxford CT 1500
HF Cryotrans system (Oxford Instruments, Eynsham, England) was mounted on a field emission SEM (model 4100; Hitachi Scientific Instruments, Mountain View, Calif.). Two segments of peel were removed from opposite sides of five apples for each of the three replications of each treatment and were mounted on a standard flat specimen holder as described by Roy et al. (1994b). The holder was rapidly plunged into liquid $\mathrm{N}$ and transferred under vacuum to a cold stage in the prechamber of the cryosystem. To sublime surface water, the frozen specimens were etched by raising the temperature of the stage in the prechamber to $-95^{\circ} \mathrm{C}$ for $8 \mathrm{~min}$, then sputter-coated with $\mathrm{Pt}$ in the prechamber, and transferred to the cryostage in the SEM for observation. The specimens were observed at a working distance of $15 \mathrm{~mm}$, and an accelerating voltage of $10 \mathrm{kV}$ was used to observe and record images on Polaroid type 55/N film.

\section{Results}

The pretreatments can be divided into four categories regarding the degree of alteration of epicuticular wax, flesh Ca concentration, and flesh firmness. The first category, consisting of the control, the distilled water pretreatment, and the Brij 30 pretreatment, had Ca concentrations ranging from 290 to $680 \mu \mathrm{g} \cdot \mathrm{g}^{-1}$ dry weight (Table 2). Fruit firmness in this group ranged from 47 to 60 $\mathrm{N}$. The second category, consisting of Tween 20 , Tween 80 , and Tergitol 15-S-9, had Ca concentrations of 980 to $1200 \mu \mathrm{g} \cdot \mathrm{g}^{-1}$ and firmnesses of 64 to $73 \mathrm{~N}$ (Table 2). The third category, consisting of Triton X-100, had a Ca concentration of $1656 \mu \mathrm{g} \cdot \mathrm{g}^{-1}$ and a firmness of $75 \mathrm{~N}$ (Table 2). Methylene chloride comprised the fourth category and was the only organic solvent used. Calcium concentration of the fruit flesh resulting from this treatment was $1790 \mu \mathrm{g} \cdot \mathrm{g}^{-1}$, and fruit firmness was $81 \mathrm{~N}$ (Table 2).

Low-temperature SEM provided a structural basis to explain the effect of surfactant treatment on the epicuticular wax platelets. Based on morphological criteria and corresponding with the $\mathrm{Ca}$ results previously presented, four categories of epicuticular wax patterns were distinguished. The first category, which includes the nontreated fruit, the water-treated fruit, and the fruit treated with Brij 30, presented a normal surface pattern. Indeed, the epicuticular wax appeared relatively smooth and exhibited numerous surface cracks that formed an interconnected network on the surface of the fruit (Fig. 1A). Typically, the cracks appeared deep and traversed through two or three layers of platelets (Fig. 1). The stereopairs (Fig $1 \mathrm{~B}$ and C) elucidate more accurately the surface topography of the cracks. The cracks appeared to result from the separation of the wax platelets that were organized in parallel horizontal layers. The slopes of the cracks consisted of single platelets organized in parallel layers. Two other categories, which included the epicuticular waxes that had been treated with surfactants containing high hydrophilelipophile balances (HLB), were distinguished by the organizational pattern of the wax platelets. The number and depth of the cracks were similar to those found in the control, indicating that the treatment with a surfactant solution does not affect the degree of cracking, but surfactant treatment 
altered the parallel organization of the wax platelets by loosening them. The second surfactant category, which included pretreatment with Tween 20 (Fig. 2A), Tween 80 (Fig. 2B), or Tergitol 15-S-9 (Fig. 2C), was characterized by slight disorganization of the wax platelets. The epicuticular wax of the fruit treated with Tween 20 had relatively unaltered cracks (Fig. 2A). However, a closer examination revealed numerous loose, nonparallel wax platelets on the slopes of the cracks. This same pattern of loose, unattached platelets also was found in epicuticular wax of fruit treated with Tergitol 15-S-9 (Fig. 2C) or Tween 80 (Fig. 2B) but to a greater extent. This disorganization also was observed at the bottom of cracks in the epicuticular wax of fruit treated with Tween 80 (Fig. 2B). The third category, which included epicuticular waxes of fruit treated with Triton $\mathrm{X}-100$, showed extensive disorganization of the wax platelets on the slopes of the cracks (Fig. 3A). Figure $3 \mathrm{~B}$ illustrates that the platelets of the epicuticular waxes were disorganized only in the cracks, even with Triton X-100, the most effective pretreatment. Finally, the fourth category, which represented the epicuticular wax of fruit treated with a solvent, $\mathrm{CH}_{2} \mathrm{Cl}_{2}$, showed a completely different pattern on the surface. The wax platelets were no longer distinguishable (Fig. 4A). Apparently, the epicuticular wax had been removed or dissolved and redeposited by the treatment (Fig. 4B). Surface injury of the fruit increased as flesh Ca concentration increased (Table 2). Fruit treated with the surfactants in the first category had little or no injury, with the injury increasing as the effectiveness of the pretreatments in allowing greater amounts of the $\mathrm{CaCl}_{2}$ solution to be infiltrated increased.

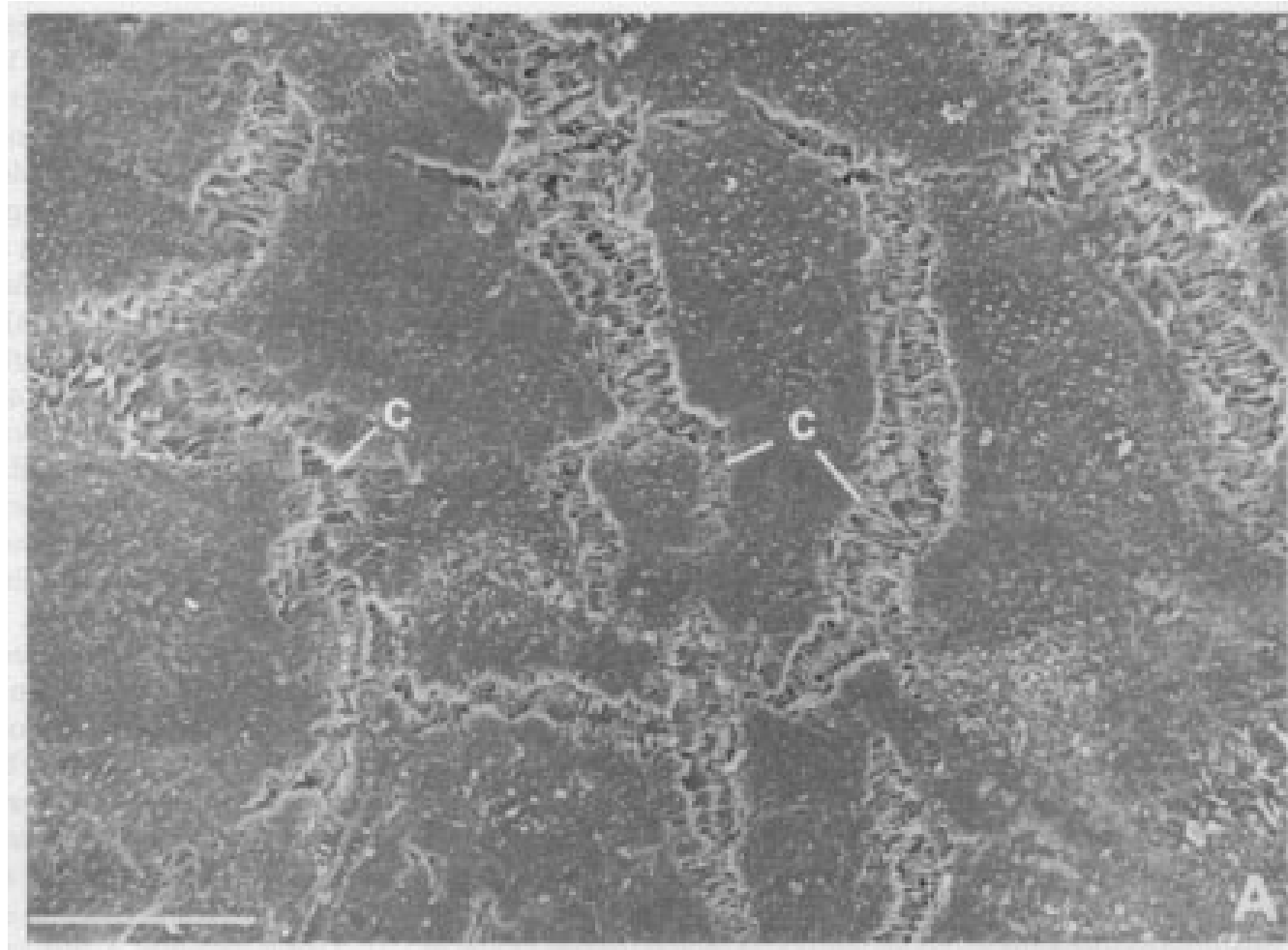

With the exception of the methylene chloride treatment, the injury covered just part of the fruit's surface, and while the injured fruit would have been unacceptable for the fresh market, they could have been used for processing. The injury on the fruit treated with methylene chloride covered the entire surface of the fruit and extended into the cortex, resulting in fruit that would be unacceptable for any purpose.

\section{Discussion}

Postharvest treatment of apples with $\mathrm{CaCl}_{2}$ solutions and the resulting increase in fruit $\mathrm{Ca}$ concentration beneficially affect fruit network. Bar $=100 \mu \mathrm{m}$. (B and $\mathbf{C})$ Complementary stereo images of the crack. To attain the three-dimensional view, place a stereo viewer on the micrographs so that the left and right lenses are aligned above the left and right images, respectively. Alternatively, a three-dimensional view can be achieved without a viewer by separately observing the left and right figure with the left and right eyes, respectively. Bar $=20 \mu \mathrm{m}$.

during storage. The surface properties of fruit, particularly those of the cuticle, affect absorption and distribution of postharvest applied chemicals. During postharvest infiltration of apples with $\mathrm{CaCl}_{2}$ solutions, $\mathrm{Ca}$ enters the fruit through lenticels (Betts and Bramlage, 1977; Harker and Ferguson, 1988) and through the calyx end. However, cracks in the cuticle are also important pathways (Glenn, et al., 1985; Harker and Ferguson, 1988). Cracks in epicuticular wax are especially prevalent in 'Golden Delicious' apples early in the growing season. These cracks increase in width and number as the apple enlarges and matures (Meyer, 1944). By the end of the growing season, large cracks form an interconnected network on the surface of apples (Faust and Shear, 1972). Lenticel 
permeability also increases during fruit development (Harker and Ferguson, 1988). Permeability to $\mathrm{CaCl}_{2}$ increases during apple development as do the number of cracks in the epicuticular wax (Glenn et al., 1985). Epicuticular cracking of apple fruit increases during the growing season, and the width and depth of the cracks continues to increase during cold storage (Roy et al., 1996). More
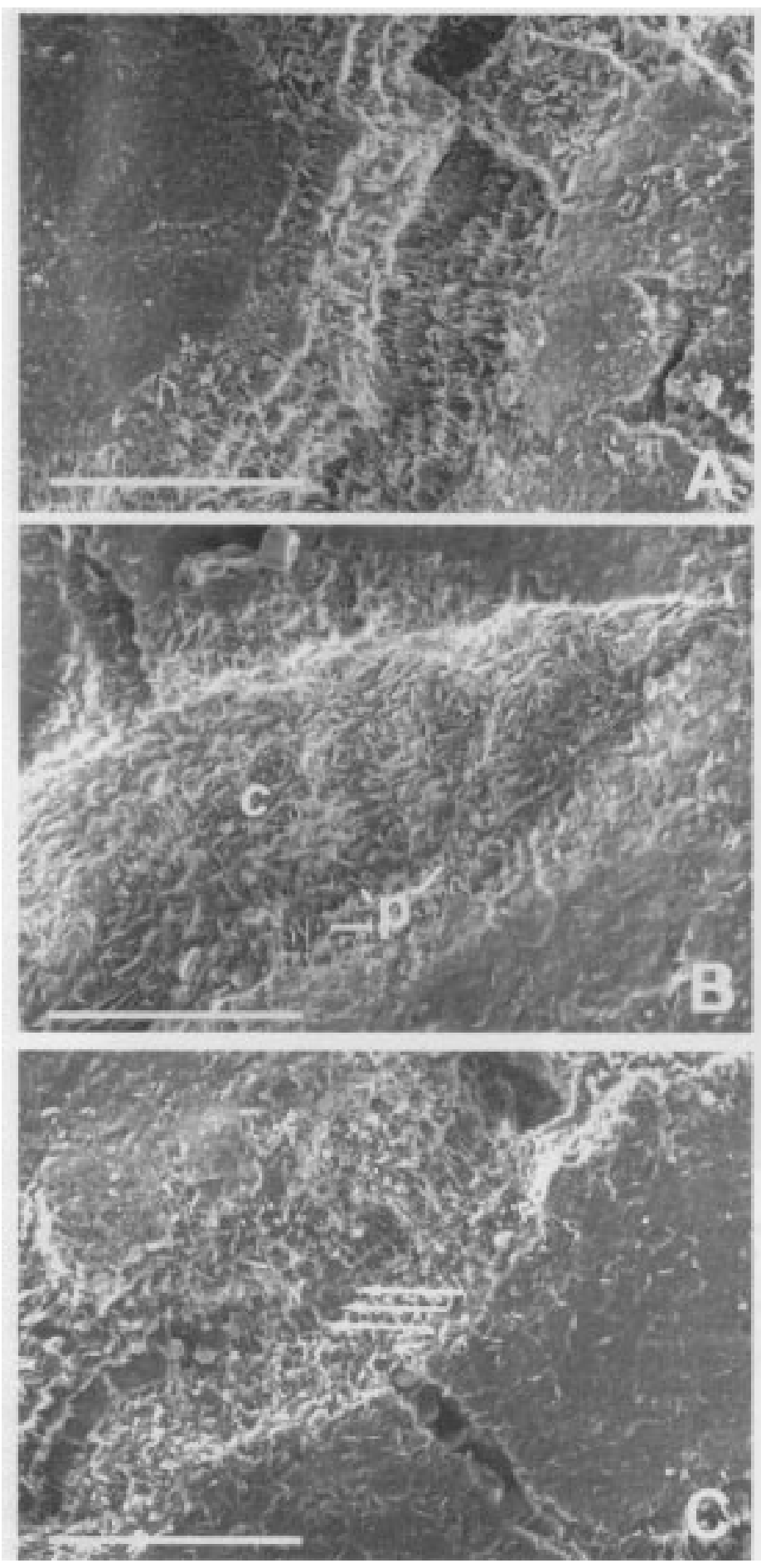

Fig. 2. Low-temperature observation of apple surfaces that have been treated before pressure infiltration. (A) Treatment with Tween 20. Classical aspect of a crack where the slopes are organized in parallel layers of wax platelets. Bar $=40 \mathrm{~m}$. (B) Treatment with Tween 80 . The slopes and the bottom of the crack are composed of platelets (p) that are organized randomly. Bar $=40 \mu \mathrm{m}$. (C) Treatment with Tergitol 15-S-9. The slopes of the crack consist of disorganized platelets. The bottom of the crack still has platelets that are parallel (arrows). Bar $=50 \mu \mathrm{m}$.
$\mathrm{CaCl}_{2}$ solution enters apples infiltrated after 6 months in storage than at harvest (C.E.S. and W.S.C., unpublished data). Alteration or modification of the structure of epicuticular wax may partially explain differences in the amount of $\mathrm{CaCl}_{2}$ absorbed by fruit during postharvest treatment. Apples pressure-infiltrated with $\mathrm{CaCl}_{2}$ solutions following prestorage heat treatment at $38{ }^{\circ} \mathrm{C}$ for $4 \mathrm{~d}$ absorbed less solution than fruit infiltrated before heat treatment (Sams et al., 1993). Heat changed the pattern of epicuticular wax on apples (Roy et al., 1994a). Pretreatment of fruit with a selected group of surfactants was performed to investigate whether chemical structural differences among nonionic surfactants affected epicuticular wax and subsequent $\mathrm{Ca}$ uptake during infiltration. These surfactants were used as surface active agents in an attempt to alter adsorption characteristics of the epicuticular wax layer on the fruit surface. Residual surfactants after pretreatment would be present to subsequently alter adsorption efficiency of the $\mathrm{Ca}$ solution during infiltration.

The surfactants were selected to cover the hydrophile-lipophile balance (HLB) range from 9.7 to 16.7 , which would be from intermediate polarity to polar on the scale of 0 to 20 usually described (Myers, 1988). This polarity range of 10 to 17 was designated best for solubilization of components at a liquid-solid interface. Structurally different hydrophobic moieties of the surfactants also were selected to investigate the possibility of alteration of surface activity by chemically different agents.

Using category 1 surfactant with HLB 9.7 (Brij 30) had no effect on Ca uptake. Pretreatment with surfactants from categories 2 and 3 with HLB ranging from 13.3 to 16.7 enhanced Ca uptake. Pretreatment with the category 2 surfactants (Tween 20, Tween 80, and Tergitol 15-S-9) resulted in similar increases of Ca uptake. These compounds had long alkyl chains as the hydrophobic portions of the surfactants in common. The surfactant in category 3 (Triton X-100) with HLB 13.5, having an alkylbenzene moiety as the hydrophobic moiety, was even more effective in increasing $\mathrm{Ca}$ uptake. The two surfactants with chain branching in the hydrophobic moiety (Tergitol 15-S-9 and Triton X-100) caused the greatest amount of $\mathrm{Ca}$ uptake among the nonionic surfactants in accord with findings that nonlinear hydrophobic substituents are better wetting agents with greater absorbing efficiency (Gray, 1965).

Using $\mathrm{CH}_{2} \mathrm{Cl}_{2}$ as a pretreatment solvent to remove lipid-soluble portions of the epicuticular wax layer on the apple surface resulted in the greatest uptake of Ca during infiltration. This harsh treatment, which resulted in unusable fruit, at least indicated that partial removal of the hydrophobic epicuticular wax components should increase $\mathrm{Ca}$ infiltration into the fruit. Using surfactants as surface active agents would be a similar but less drastic treatment to solubilize these components and enhance $\mathrm{Ca}$ uptake by alterations of the epicuticular wax structure.

Treatments with some surfactants result in different degrees of disruption and reorganization of the wax platelets in the cracks. Apparently, these surfactants detach or loosen the wax platelets and reorient them. Several possibilities may explain why pretreatment with a surfactant results in increased uptake of an infiltrated Ca solution. The wettability of the surface may have been modified in several ways. Wetting is affected by surface morphology, gross and micro (Bukovac et al, 1981). The surfactant treatment altered the surface morphology by changing the horizontal and parallel organization of the wax platelets into a more random distribution. This will not only increase the contact area between the droplets of solution and the surface but also will trap the solution and create channels toward the bottom of the cracks. Therefore, the altered surface fine structure becomes a critical factor that determines 

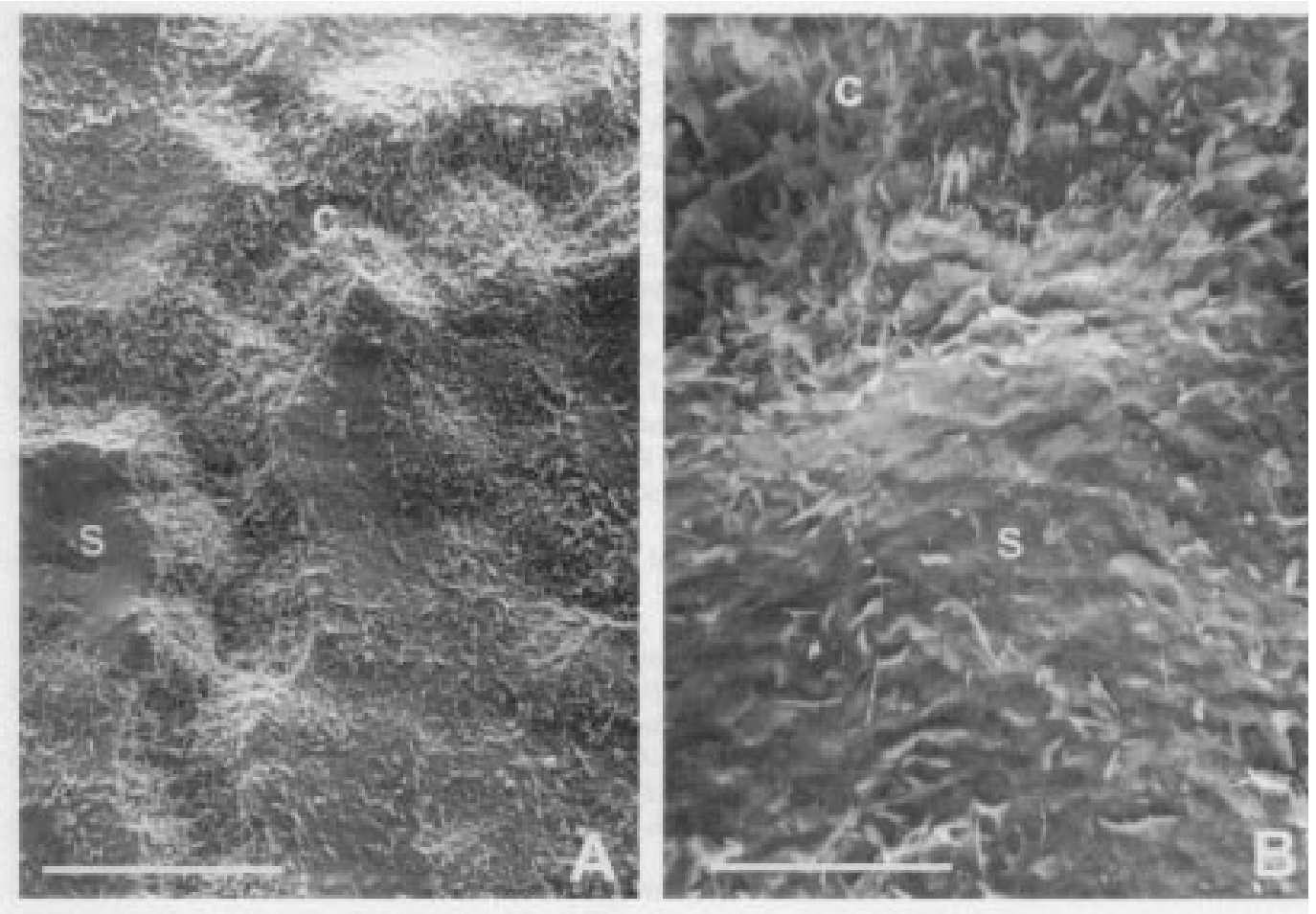

Fig. 3. Low-temperature observation of apple surfaces that have been treated with Triton X-100. (A) The pattern of the platelets appear disorganized on the slopes of the cracks. Bar $=100 \mu \mathrm{m}$. (B) Detail illustrating the difference in the organizational pattern of the platelets between the slopes of the cracks and the epicuticular wax surface (s). Bar $=30$ $\mu \mathrm{m}$.
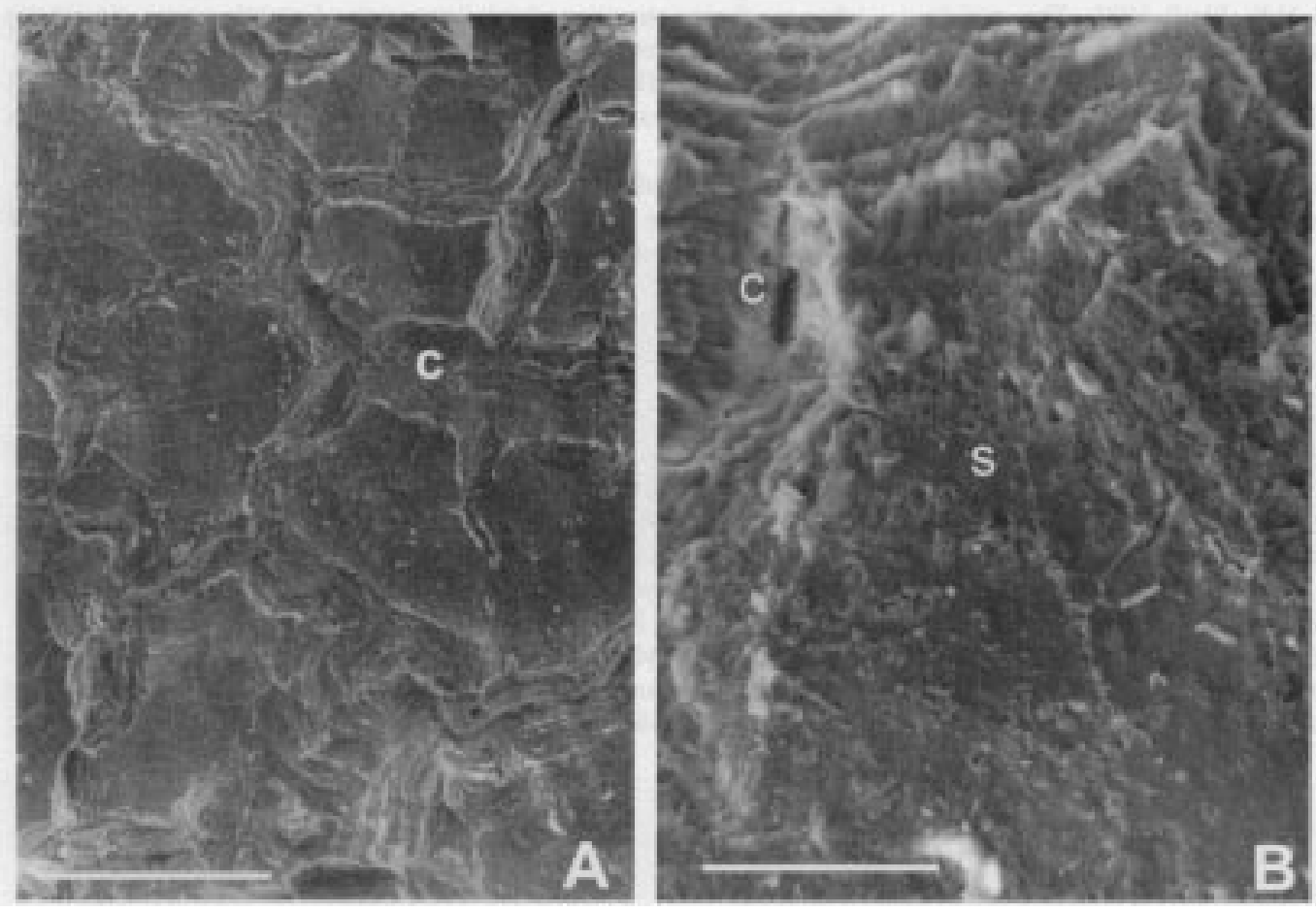

Fig. 4. Low-temperature observation of apple surfaces that have been treated with $\mathrm{CH}_{2} \mathrm{Cl}_{2}$. (A) The cracks are still present but the slopes are eroded. The bottom of the cracks appear as a deep canyon. $\mathrm{Bar}=150$ $\mu \mathrm{m}$. (B) Detail. No epicuticular wax platelets are distinctly visible in the crack (c). $\mathrm{s}$ : epicuticular wax surface. Bar $=30 \mu \mathrm{m}$.

$\mathrm{CaCl}_{2}$ solution availability for penetration into the underlying tissue. The wettability of the surface can be modified by the structure of the surfactant used, particularly the hydrophobic moiety, which could result in either a selective solubilization of the components of the epicuticular wax or in a more polar chemical environment that influences the sorption (Shafer and Bukovac, 1987). Another possibility is that solubilization of certain chemical components of the epicuticular wax would have occurred due to the surfactant pretreatment. Harker and Ferguson, 1991, reported that Tween 20 increased $\mathrm{Ca}$ transport by altering permeability of intact cuticles not containing cracks or functional lenticels. The treatment may have altered the epicuticular wax barrier by decreasing its thickness. For example, the pretreatment with $\mathrm{CH}_{2} \mathrm{Cl}_{2}$ appears to have removed a major portion of the epicuticular wax, disrupted the wax structure, and resulted in the greatest uptake of $\mathrm{Ca}$. As lesser disruptions occurred, less $\mathrm{Ca}$ was absorbed but less injury occurred. The ultimate goal of our research was to find the optimum surfactant pretreatment that alters the epicuticular wax sufficiently to increase Ca uptake but not severely enough to injure the fruit as the methylene chloride did.

One of the major problems limiting the commercial adaptation of postharvest infiltration of apples to maintain fruit quality in 
storage is the fruit surface injury caused by $\mathrm{CaCl}_{2}$ solutions (Conway et al., 1994). Apple flesh Ca concentration must be $\approx 1200 \mu \mathrm{g} \cdot \mathrm{g}^{-1}$ dry weight to beneficially affect fruit softening and decay (Conway and Sams, 1985; Sams and Conway, 1984). Increasing flesh $\mathrm{Ca}$ above this point increases fruit surface injury. Pretreatment with Triton $\mathrm{X}-100$ before a $2 \% \mathrm{CaCl}_{2}$ infiltration results in a flesh concentration of $\approx 1700 \mu \mathrm{g} \cdot \mathrm{g}^{-1}$. Thus, a 1200 $\mu \mathrm{g} \cdot \mathrm{g}^{-1}$ concentration may be reached with a lower $\mathrm{CaCl}_{2}$ solution concentration combined with a surfactant pretreatment as effective as Triton X-100. Fruit injury may be significantly reduced or totally prevented. Surfactant pretreatment also may allow greater absorption of $\mathrm{Ca}$ by fruit merely dipped in solutions of $\mathrm{CaCl}_{2}$ and negate the necessity for the more complex infiltration treatments.

\section{Literature Cited}

Attwood, D. and A.T. Florence. 1983. Surfactant systems: Their chemistry, pharmacy and biology. Chapman \& Hall, London.

Bangerth, F., D.R. Dilley, and D.H. Dewey. 1972. Effect of postharvest calcium treatments on internal breakdown and respiration of apple fruits. J. Amer. Soc. Hort. Sci. 97:679-682.

Betts, H.A. and W.J. Bramlage. 1977. Uptake of calcium by apples from postharvest dips in calcium chloride solutions. J. Amer. Soc. Hort. Sci. 102:785-788.

Bukovac, M.J. and P.D. Petracek. 1993. Characterizing pesticide and surfactant penetration with isolated plant cuticles. Pestic. Sci. 37:179194.

Bukovac, M.J., H.P. Rasmussen, and V.E. Shull 1981. The cuticle: Surface, structure and function. Scann. Electr. Microsc. III:213-223.

Conway, W.S. and C.E. Sams. 1983. Calcium infiltration of 'Golden Delicious' apples and its effect on decay. Phytopathology 73:10681071.

Conway, W.S. and C.E. Sams. 1985. Influence of fruit maturity on the effect of postharvest calcium treatment on Golden Delicious apples. Plant Dis. 69:42-44.

Conway, W.S., C.E. Sams, G.A. Brown, W.B. Beavers, R.B. Tobias, and L.S. Kennedy. 1994. Pilot test for the commercial use of postharvest infiltration of calcium into apples to maintain fruit quality in storage. HortTechnology 4:239-243.

Conway, W.S., C.E. Sams, R.G. McGuire, and A. Kelman. 1992. Calcium treatment of apples and potatoes to reduce postharvest decay. Plant Dis. 76:329-334.

Drake, M., W.J. Bramlage, and J.H. Baker. 1979. Effects of foliar calcium on 'McIntosh' apple storage disorders. Commun. Soil Sci. Plant Anal. 10:303-309.

Faust, M. and C.B. Shear. 1968. Corking disorders of apples: A physiological and biochemical review. Bot. Rev. 34:441-469.

Faust, M. and C. B. Shear. 1972. Fine structure of the fruit surface of three apple cultivars. J. Amer. Soc. Hort. Sci. 97:351-355.
Glenn, G.M., and B.W. Poovaiah. 1985. Cuticular permeability to calcium compounds in 'Golden Delicious' apple fruit. J. Amer. Soc Hort. Sci. 110:192-195.

Glenn, G.M., B.W. Poovaiah, and H.P. Rasmussen. 1985. Pathways of calcium penetration through isolated cuticles of 'Golden Delicious' apple fruit. J. Amer. Soc. Hort. Sci. 110:166-171.

Gray, F.W., I.J. Krems, and J.F. Gerecht. 1965. Detersive properties of model straight chain sodium alkylbenzene-sulfonates. J. Amer. Oil Chem. Soc. 42:998-1001.

Harker, F.R. and I.B. Ferguson. 1988. Transport of calcium across cuticles isolated from apple fruit. Sci. Hort. 36:205-217.

Harker, F.R. and I.B. Ferguson. 1991. Effects of surfactants on calcium penetration of cuticles isolated from apple fruit. Sci. Hort. 46:225-233.

Knoche, M., P.D. Petracek, M. J. Bukovac, and W.E. Shafer. 1994. Urea penetration of isolated tomato fruit cuticles. J. Amer. Soc. Hort. Sci. 119:761-764.

Marlow, G.C. and W.H. Loescher. 1984. Watercore. Hort. Rev. 6:189251.

Meyer, A. 1944. A study of the skin structure of 'Golden Delicious' apples. Proc. Amer. Soc. Hort. Sci. 45:723-727.

Myers, D. 1988. Emulsions, p. 209-250. In: D. Myers (ed.). Surfactant science and technology. VCH Publishers, New York.

Reid, M.S. and C.A.S. Padfield. 1975. Control of bitter pit in apples with lecithin and calcium. N.Z. J. Expt. Agr. 7:379-381.

Rosen, M.J. 1978. Surfactants and interfacial phenomena. Wiley, New York.

Roy, S., W.S. Conway, A.E. Watada, C.E. Sams, and W.P. Wergin. 1996. Low-temperature SEM of the epicuticular wax of apples: Structural changes during storage and calcium uptake. Food Structure. (In press.)

Roy, S., W.S. Conway, A.E. Watada, C.E. Sams, E.F. Erbe, and W.P. Wergin. 1994a. Heat treatment affects epicuticular wax structure and postharvest calcium uptake in 'Golden Delicious' apples. HortScience 29:1056-1058.

Roy, S., A.E. Watada, W.S. Conway, E.F. Erbe, and W.P. Wergin. 1994b. Low-temperature scanning electron microscopy of frozen hydrated tissues and surface organisms. HortScience 29:305-309.

Sams, C.E. and W. S. Conway. 1984. Effect of calcium infiltration on ethylene production, respiration rate, soluble polyuronide content, and quality of 'Golden Delicious' apples. J. Amer. Soc. Hort. Sci. 109:5357.

Sams, C.E, W.S. Conway, J.A. Abbott, R.J. Lewis, and N. Ben-Shalom. 1993. Firmness and decay of apples following postharvest infiltration of calcium and heat treatment. J. Amer. Soc. Hort. Sci. 118:623-623.

Schonherr, J. and M. Riederer. 1989. Foliar penetration and accumulation of organic chemicals in plant cuticles, p. 1-70. In: F.A. Gunther (ed.). Reviews of environmental contamination and toxicology. vol. 108. Springer Verlag, New York.

Shafer, W.E. and M.J. Bukovac. 1987. Studies on Octylphenoxy surfactants. III. Sorption of Triton X-100 by isolated fruit cuticles. Plant Physiol. 85:965-970. 